\title{
PERANCANGAN ALAT UKUR TDS (TOTAL DISSOLVED SOLID) AIR DENGAN SENSOR KONDUKTIVITAS SECARA REAL TIME
}

\author{
Ronaldi Zamora $^{1}$ Harmadi $^{2}$ dan Wildian ${ }^{2}$

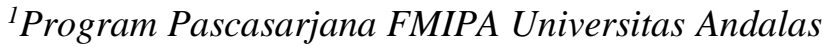 \\ ${ }^{2}$ Departemen Fisika, FMIPA Universitas Andalas, Padang 25163 \\ ${ }^{1}$ ronaldizamoras2@yahoo.com; ${ }^{2}$ harmadi@fmipa.unand.ac.id
}

\begin{abstract}
An experiment was done to design of conductivity sensor for real time measurement of TDS (Total Dissolved Solid) in water. The instrument system incluedes hardware and software systems. The hardware system consist conductivity sensor, microcontroller arduino uno, and a PC. While the software system covers the procces and making on display measurement result based on LabVIEW. TDS information is displayed in the form of digital, analog and graph in real time. Another advantage of this measurement system is that the TDS data can be stored in file format xlxs. The measurement data is done by comparing the system is designed with a standard measuring instrument that is TDS EZDO E 7200. The data obtained through measurement errors were analyzed using the theory and methods of the graph. Based on the analysis conducted found the output voltage of the conductivity sensor rises with the increase in water with a sensitivity of 0,924 $\mathrm{mV} / \mathrm{ppm}$. The instrument of TDS measurement data has an accuracy rate of $97.17 \%$
\end{abstract}

Keyword: microcontroller, water, TDS, LabVIEW

\section{PENDAHULUAN}

Sekitar $70 \%$ tubuh manusia terdiri dari air. Kebutuhan tubuh terhadap air umumnya dipenuhi melalui asupan air minum dan makanan. Kebutuhan air minum setiap orang bervariasi, bergantung pada berat badan dan aktivitasnya. Dewasa ini banyak masyarakat di daerah perkotaan yang menggunakan air minum dalam kemasan plastik yang biasa disebut gallon. Syarat baku mutu air minum sebagaimana yang disyaratkan oleh Kementerian Kesehatan (kepmenkes,2010), yaitu tidak berasa, tidak berbau, tidak berwarna, tidak mengandung mikroorganisme yang berbahaya, dan tidak mengandung logam berat. Air minum yang terkontaminasi dapat menimbulkan masalah kesehatan seperti antara lain kanker, gangguan pada bayi yang dilahirkan, kerusakan jaringan saraf pusat dan penyakit jantung (Sawyer, 1994).

Salah satu faktor penting dalam menentukan kelayakan air untuk dikonsumsi manusia adalah kandungan TDS (total dissolved solid) dalam air. TDS adalah jumlah zat padat terlarut baik berupa ion-ion organik, senyawa, maupun koloid didalam air (WHO, 2003). Konsentrasi TDS yang terionisasi dalam suatu zat cair mempengaruhi konduktivitas listrik zat cair tersebut. Makin tinggi konsentrasi TDS yang terionisasi dalam air, makin besar konduktivitas listrik larutan tersebut. Sementara konsentrasi TDS juga dipengaruhi oleh temperatur (Bevilacqua, 1998). Konsentrasi TDS dalam air minum melebihi batas ambang yang diperbolehkan dapat membahayakan kesehatan karena dapat menyebabkan terjadinya gangguan pada ginjal. Menurut WHO (World Health Organization), air minum yang layak dikonsumsi memiliki kadar TDS < 300 ppm (parts per million). Sedangkan menurut Peraturan Menteri Kesehatan Republik Indonesia nomor 492 tahun 2010 menyatakan standar TDS maksimum yang diperbolehkan adalah $500 \mathrm{mg} / \mathrm{liter}$ atau 500 ppm. 
Dalam mengembangkan alat ukur untuk kebutuhan khusus diperlukan analisis dan kajian yang mendalam terhadap hasil yang dikeluarkan dari alat ukur yang dikembangkan. Sistem alat ukur seperti ini biasa disebut dengan sistem akuisisi data. Sistem Akuisisi data dapat didefinisikan sebagai suatu sistem yang berfungsi untuk mengambil, mengumpulkan, dan menyiapkan data, hingga memprosesnya untuk menghasilkan data yang dikehendaki (Howard, 2003). Sistem akuisisi data dapat mengkonversi besaran fisis data source ke bentuk sinyal digital dan diolah oleh suatu PC serta menampilkan grafik besaran fisis terhadap waktu melalui layar monitor. Pengolahan data dan pengontrolan yang dilakukan oleh PC memungkinkan penginterpretasian data dapat dengan mudah dilakukan. Selain itu data pengukuran dapat disimpan sehingga dapat dipanggil kembali jika diinginkan pada saat mendatang.

Pada penelitian ini dirancang suatu perangkat sistem akuisi data TDS (Total Dissolved Solid) air minum yang dihubungkan dengan sensor konduktivitas dan sensor LM35. Prinsip kerja sensor konduktivitas didasarkan pada pengaliran arus kedalam zat cair dengan menggunakan dua probe yang terbuat dari stainless dengan jarak $1 \mathrm{~cm}$ yang berfungsi untuk mendapatkan nilai konduktansi suatu larutan. Besarnya nilai konduktansi bergantung kepada ion organik, suhu dan konsentrasi ion (Mahid, 1986). Semakin besar nilai konduktivitas mengindikasikan semakin banyak mineral yang terkandung dalam air. Hubungan antara TDS dan konduktivitas dinyatakan dalam persamaan 1 (Efendi, 2003)

$$
\begin{aligned}
& T D S(\mathrm{ppm})=E C(\mu \mathrm{S} / \mathrm{cm} \\
& \text { pada } \left.25^{\circ} \mathrm{C}\right) \times 0,64
\end{aligned}
$$

dengan TDS adalah jumlah zat terlarut dengan satuan (ppm), dan $E C$ adalah konduktivitas listrik diukur pada $25^{\circ} \mathrm{C}$ dengan satuan $(\mu \mathrm{S} / \mathrm{cm})$

\section{METODE PENELITIAN}

Sistem pengukuran TDS air minum ini dilakukan berdasarkan kemampuan kation dan anion untuk menghantarkan arus listrik, semakin besar nilai konduktansi maka semakin besar kemampuan kation dan anion dalam menghantarkan arus listrik. Secara umum blok diagram sistem secara keseluruhan dapat diperhatikan pada Gambar 1.

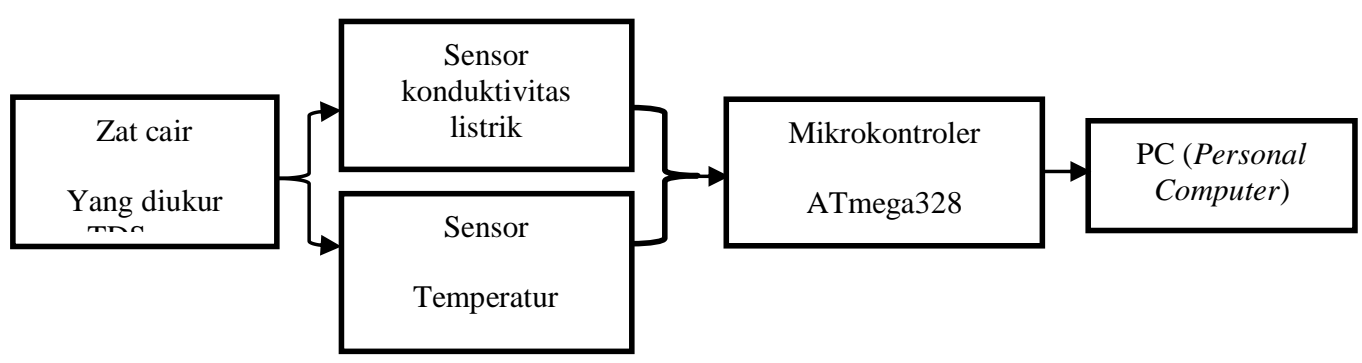

Gambar 1 Blok diagram sistem keseluruhan

Alat ukur TDS dalam air menggunakan sistem sensor konduktivitas dengan dua probe yang terbuat dari stainless. Sebagai sumber tegangan untuk sensor konduktivitas yaitu catudaya $12 \mathrm{~V}$. Secara umum desain perangkat keras sistem pengukuran TDS air minum dapat dilihat pada Gambar 2.
Dari Gambar 2 menunjukkan desain secara umum terdiri dari atas tiga bagian, yaitu sensor konduktivitas dan sensor temperatur, mikrokontroler sebagai pengkondisi sinyal dan penampil $(P C)$. Dalam sensor konduktivitas, pengaliran arus listrik searah ke dalam zat cair, sangat rentan terjadi elektrolisis dan perubahan kepolaran ion-ion. Untuk menjaga supaya tidak terjadi elektrolisis digunakan sumber tegangan 
AC konstan pada probe agar pada larutan dapat terjadi aliran arus dan mengkonversi nilai konduktansi menjadi tegangan. Sumber tegangan yang digunakan pada sinyal processing adalah $12 \mathrm{~V}$. Sementara sensor temperatur LM35 yang berfungsi untuk mengubah besaran temperatur menjadi besaran listrik dalam bentuk tegangan. Besaran tegangan yang dihasilkan oleh sinyal processing diubah menjadi nilai digital melalui mikrokontroler arduino dan mengkonversinya menjadi satuan ppm serta menampilkannya pada PC (Personal Computer)

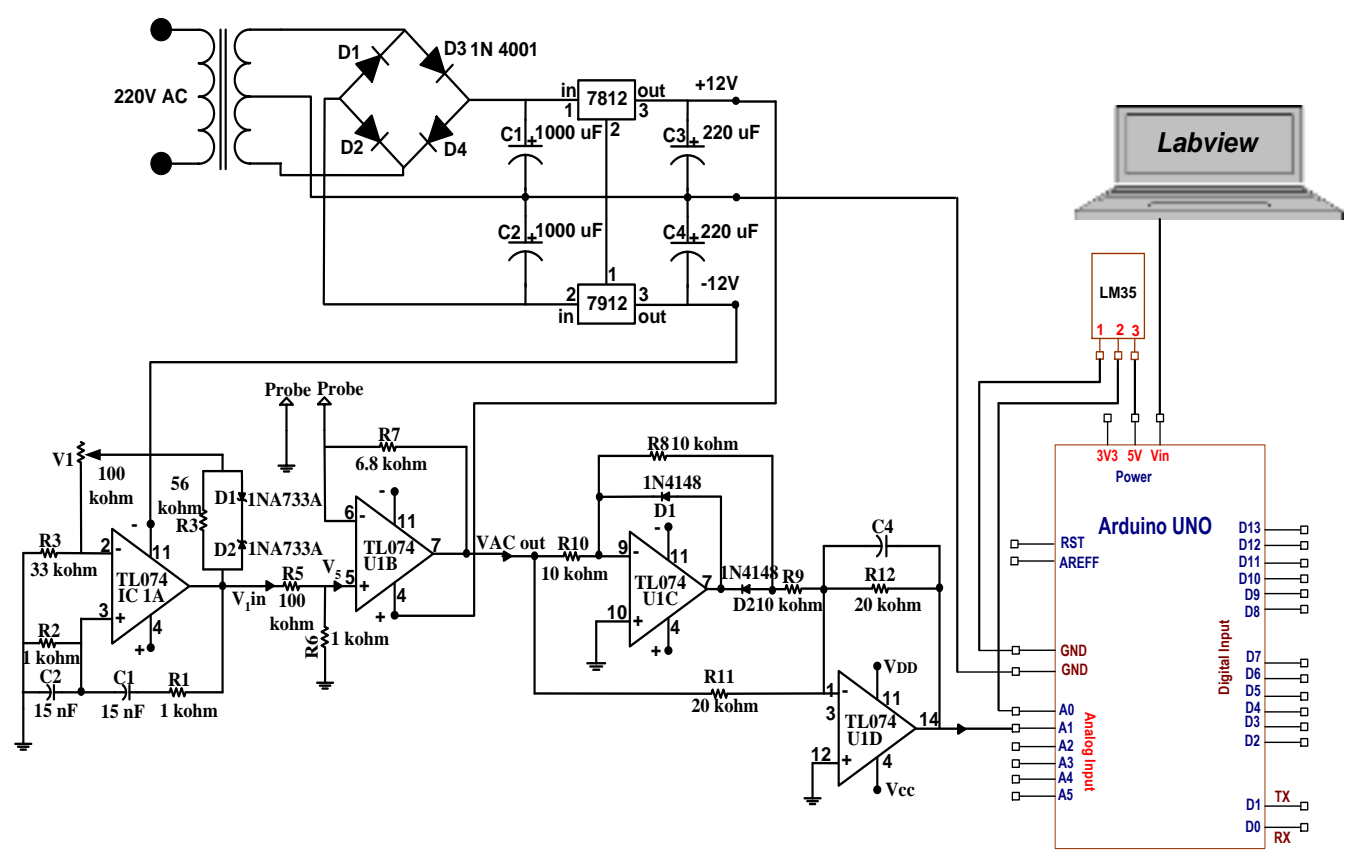

Gambar 2 Desain Perangkat Keras Sistem Pengukuran TDS dalam Air

\section{HASIL DAN PEMBAHASAN}

Hasil pengukuran yang telah didapatkan dalam pengukuran TDS dalam air menggunakan sensor konduktivitas ditampilkan dalam bentuk grafik pada Gambar 3 .

Dari Gambar 3 terlihat bahwa tegangan keluaran sensor konduktivitas seiring dengan peningkatan nilai TDS air yang diukur dengan TDS EZDO 7200 berdasarkan Persamaan 1 seperti terlihat pada Tabel 1.

Dari Gambar 3 terlihat bahwa tegangan keluaran sensor semakin naik seiring peningkatan nilai TDS air yang diukur dengan TDS EZDO 7200. Kenaikan tegangan keluaran sensor berhubungan secara linier dengan TDS air. Melalui pendekatan garis lurus diperoleh persamaan $\mathrm{y}=0,924 \mathrm{x}+88,179$, dimana angka
0,924 menyatakan sensitivitas sensor. Besarnya sensitivitas sensor adalah 0,924 $\mathrm{mV} / \mathrm{ppm}$, artinya setiap kenaikan nilai TDS 1 ppm sampel maka tegangan keluaran sensor akan naik sebesar $0,924 \mathrm{mV}$. Tanda positif berarti tegangan keluaran naik dengan peningkatan nilai TDS. Angka 88,179 merupakan tegangan keluaran (dalam V) pada saat nilai TDS mendekati nol. Dari hasil analisis data pada Tabel 2 dapat dijelaskan tingkat ketelitian dari pengukuran. Kesalahan relatif dari sistem pengukuran TDS air berkisar antara 0,11\% sampai $7,80 \%$. Ketelitian pengukuran dibandingkan dengan TDS EZDO E7200 memiliki perbedaan nilai TDS maksimal kurang dari 3 ppm Secara keseluruhan desain alat yang telah dibuat dapat dilihat pada Gambar 4. 


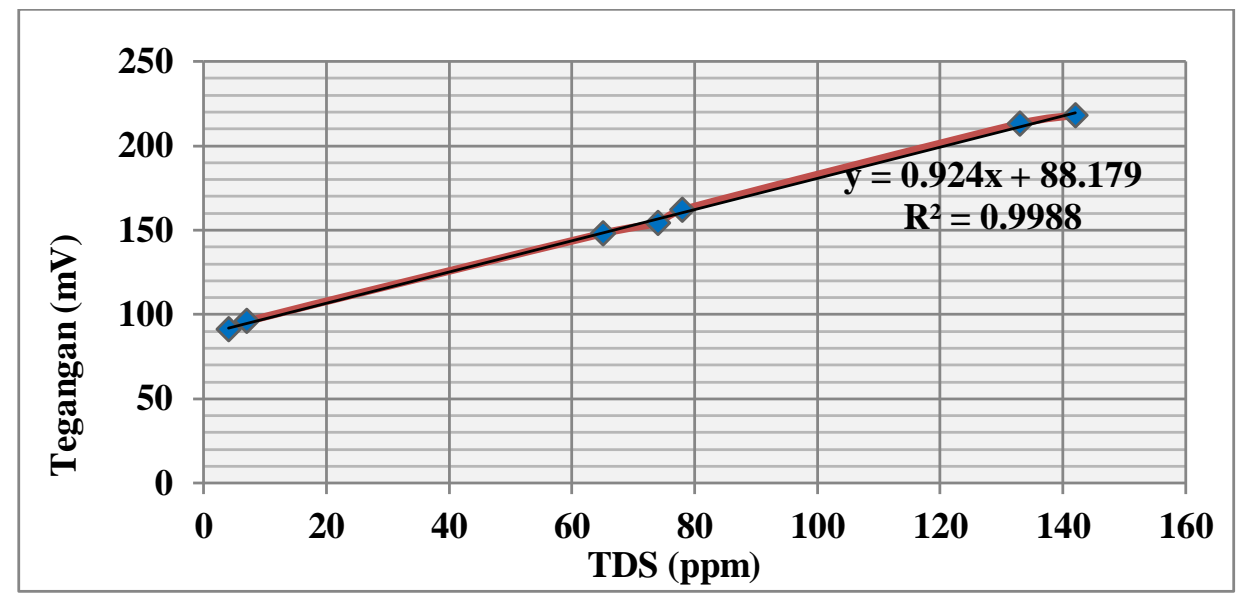

Gambar 3 Hubungan antara TDS dan tegangan keluaran

Tabel 1 Data Ketelitian Pengukuran

\begin{tabular}{|c|c|c|c|c|c|c|}
\hline \multirow[t]{2}{*}{ Sampel } & \multirow{2}{*}{$\begin{array}{l}\text { TDS }_{\text {ukur }} \\
\text { (ppm) }\end{array}$} & \multicolumn{3}{|c|}{$\begin{array}{l}\text { Pengukuran berulang terhadap sensor } \\
\text { konduktivitas }\end{array}$} & \multirow{2}{*}{$\begin{array}{l}\mathrm{TDS}_{\text {dibuat }} \\
\text { (ppm) }\end{array}$} & \multirow{2}{*}{$\begin{array}{l}\text { Kesalahan } \\
\text { Relatif (\%) }\end{array}$} \\
\hline & & $\mathrm{X}_{1}$ & $X_{2}$ & $\mathrm{X}_{3}$ & & \\
\hline I & 8 & 8,32 & 7,83 & 8,70 & 8,28 & 3,50 \\
\hline II & 65 & 65,00 & 65,36 & 65,36 & 65,57 & 0,87 \\
\hline III & 73 & 68,60 & 66,65 & 66,65 & 67,30 & 7,80 \\
\hline IV & 78 & 74,76 & 73,80 & 76,40 & 74,99 & 3,86 \\
\hline $\mathrm{V}$ & 133 & 132,30 & 133,61 & 133,61 & 133,14 & 0,11 \\
\hline \multirow[t]{2}{*}{ VI } & 140 & 138,81 & 138,81 & 138,81 & 138,81 & 0,85 \\
\hline & & & & & Rata-Rata & 2,83 \\
\hline
\end{tabular}

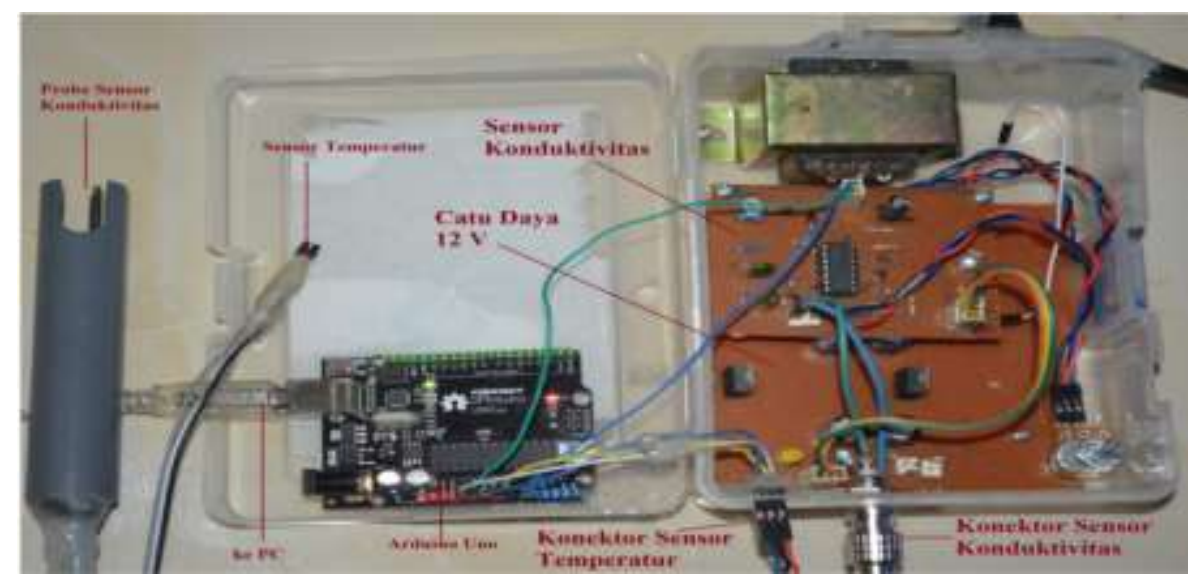

Gambar 4 Rangkaian Keseluruhan Alat Ukur TSS Air

Nilai sensitivitas yang didapatkan akan dimasukkan kedalam program LabView sebagai fungsi transfer. Pada program LabView juga didesain tampilan secara real time untuk mengetahui perubahan nilai TDS berdasarkan waktu pengamatan. Pengamatan dalam jangka 
waktu 180 detik, nilai rata-rata TDS dari 20 data tidak mengalami perubahan yang signifikan. Selain itu hasil pengukuran bisa disimpan dalam MS. Excell pada PC. Tampilan program LabView pada PC dapat dilihat pada Gambar 5.

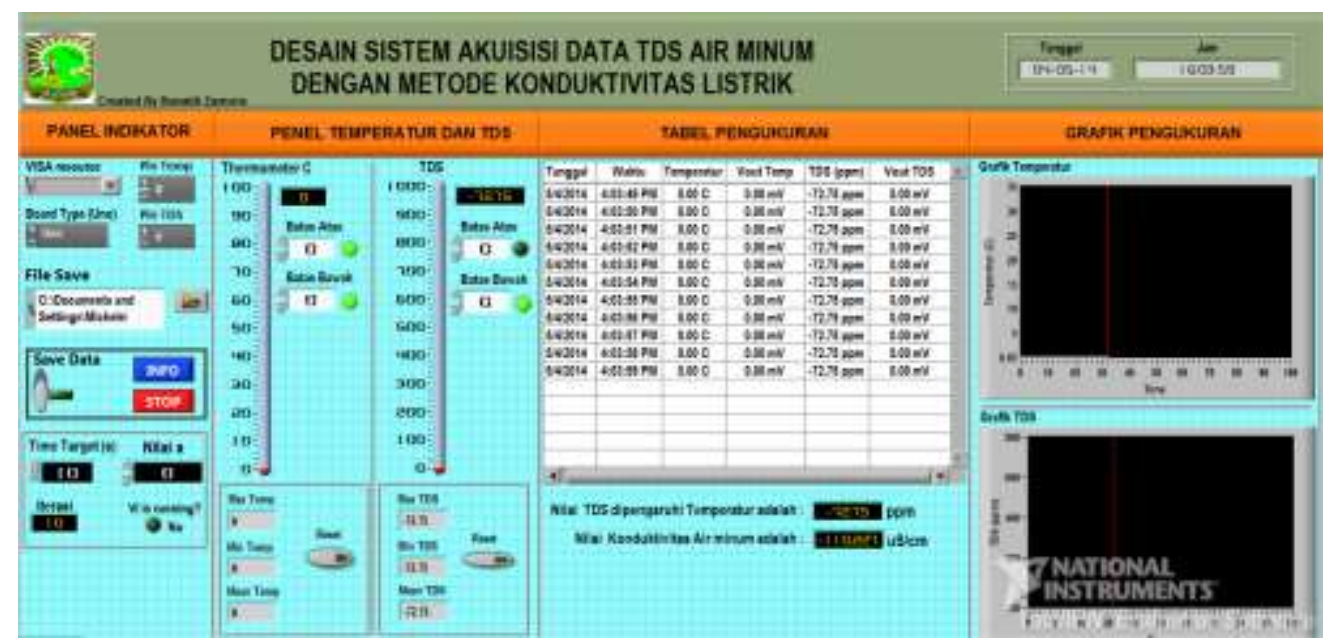

Gambar 5 Tampilan Program LabView untuk Pengukuran TDS Air

\section{KESIMPULAN DAN SARAN}

\section{Kesimpulan}

Berdasarkan data hasil dan analisis terhadap besaran yang terdapat dalam sistem pengukuran TDS air menggunakan sensor konduktivitas dapat ditarik kesimpulan bahwa besarnya sensitivitas sensor konduktivitas adalah $0,924 \mathrm{mV} / \mathrm{ppm}$, artinya setiap kenaikan nilai TDS $1 \mathrm{ppm}$ sampel maka tegangan keluaran sensor akan naik sebesar $0,924 \mathrm{mV}$. Persentase kesalahan dari sistem pengukuran TDS air berkisar antara 0,11\% sampai 7,80\%. Ketelitian pengukuran dibandingkan dengan TDS EZDO E7200 memiliki perbedaan nilai TDS maksimal kurang dari 3 ppm.

\section{Saran}

Berdasarkan pembahasan yang telah dilakukan maka dapat dikemukakan saran sebagai berikut yaitu perlu diteliti lebih dalam lagi beberapa jenis probe berdasarkan jenis material elektroda misalnya platina, geometri dan desain sehingga didapatkan data yang lebih presisi.

\section{DAFTAR KEPUSTAKAAN}

A.C. Bevilacqua, 1998. The standard fo Resistivity Measurements of Ultrapure Water. Semiconductor Pure Water and Chemicals Conference, Massachusetts.

Effendi, H, 2003, Telaah Kualitas Air Bagi Pengelolaan Sumber Daya dan Lingkungan Perairan. Yogyakarta: Kanisius.

Howard, A., 2003, Data Acquisition Techniques Using PC's. San Diego: Academic Press.

Kementerian Kesehatan, 2010, Undang-Undang Nomor 492 Tahun 2010 tentang Persyaratan Kualitas Air Minum, Jakarta.

Mahida, U.N. 1986. Pencemaran dan Pemanfaatan Limbah Industri. Jakarta: Rajawali Press.

Sawyer, C. N., 1994. Chemistry For Environmental Engeneering, Fourth Edition. Singapore: McGraw-Hill Inc.

WHO, 2003. Total dissolved solids in Drinkingwater. Geneva Switzerland: World Health Organization. 